\title{
Optimization Plug Mode of External Fuel and Weapons for Less Changing Aircraft Center of Gravity
}

\author{
Zeyang Zhou, Jun Huang, Mingxu Yi, and Guo Zhong \\ School of Aeronautic Science and Engineering, Beijing University of Aeronautics and Astronautics, Beijing 100191, China \\ Correspondence should be addressed to Mingxu Yi; yimingxu88@163.com
}

Received 13 January 2017; Revised 14 March 2017; Accepted 20 April 2017; Published 18 June 2017

Academic Editor: Ilhan Tuzcu

Copyright (c) 2017 Zeyang Zhou et al. This is an open access article distributed under the Creative Commons Attribution License, which permits unrestricted use, distribution, and reproduction in any medium, provided the original work is properly cited.

\begin{abstract}
To achieve the minimum change of aircraft center of gravity, plug mode optimization was carried out. Plug mode, including weight and position of external fuel and weapon load, was selected as design mode. Numerical model for calculating aircraft center of gravity was established and used to generate mode samples. Random search algorithm (RSA) was designed and applied for solving the optimization plug mode, and the precise solution of plug mode was determined by full array method (FAM). Compared with typical plug mode, the optimization mode can reach a minimum change in aircraft center of gravity with fewer samples than the solution by FAM. RSA coupled with FAM is an effective scheme for the optimization of aircraft plug mode.
\end{abstract}

\section{Introduction}

Demands for more fuel and weapons plug and smaller change of aircraft center of gravity have caused aircraft designers and staff to develop system or model to determine aircraft center of gravity. Han et al. developed an adaptive nonsingular fast terminal sliding mode control for aircraft with center of gravity variations to improve the dynamic and the quality characteristics of the aircraft [1]. Yang et al. established aircraft center of gravity estimation using Gaussian process regression models [2]. An aircraft weight and center of gravity indicator system was developed [3]. Gupta et al. proposed a finite element based structural model of a small flexible aircraft, focusing on obtaining a simple model suitable for control design based on a two-step procedure [4]. Li et al. analyzed the position of center of gravity for an unmanned aerial vehicle based on load task [5].

Much work has been done on the influence of aircraft center of gravity on flight performance and aerodynamic characteristics. Li et al. did research on effects of partial fuel pump failure on center of gravity control for high-speed aircraft to gain potential performance benefits. Besides, the influence of partial fuel transfer line leak on active center of gravity control was analyzed [6,7]. Jungo et al. investigated the development of the CEASIOM aircraft design environment for novel aircraft configurations and analyzed static and dynamic stability of the aircraft [8]. Mardanpour et al. did research on engine placement effect on nonlinear trim and stability of flying wing aircraft [9]. Zhen probed into the CG position of minimum drag to check stability boundary and front control boundary for J-7 aircraft [10]. An analytical expression was developed which showed that wing/tail interference drag was determined by wing downwash at downstream infinity $[11,12]$. Wang et al. did optimization design of unmanned aerial vehicle with considering the uncertainty of the center of gravity and the influence of the center of gravity on the navigation time is greatly reduced [13]. Diekmann did trim analysis of nonlinear flight dynamics for a civil aircraft with active high-lift system [14]. Tang et al. put forward a calculation and analysis method for aircraft center of gravity to improve flight performance and safety [15].

Developing an efficient design and optimization method for plug systems is attracting more and more attention from researchers. Dancila et al. researched fuel burn prediction algorithm for cruise, constant speed, and level flight segments and considered the continuous fuel burn rate variation with time caused by the gross weight modification due to the fuel burn process itself [16]. Patron et al. put forward low calculation time interpolation method on the altitude optimization algorithm for the FMS CMA-9000 improvement on the A310 and L-1011 aircraft [17]. Ivester et al. worked on compact aircraft galley and lavatory arrangement and articulating 


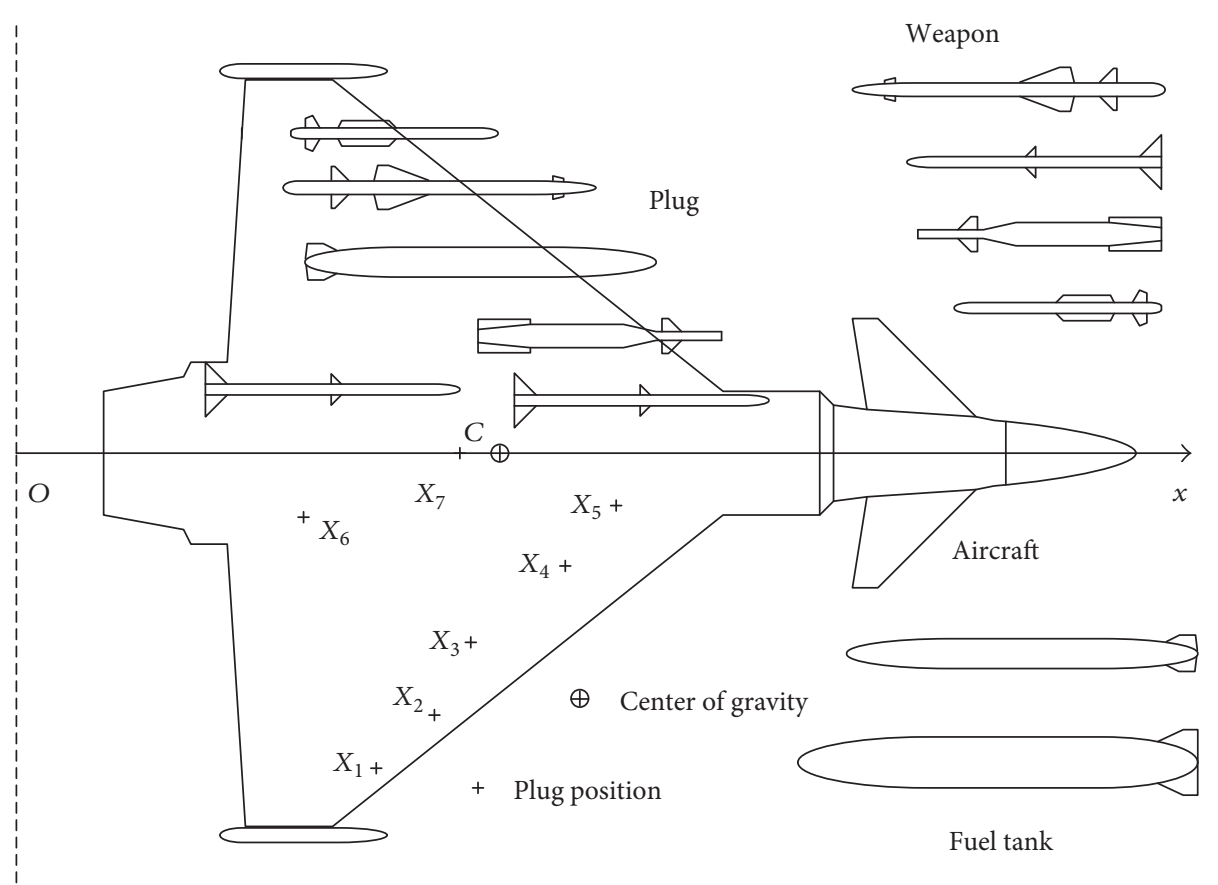

FIgURE 1: Plug and spare load schematic, symmetrical loading.

lavatory partition for an aircraft [18]. Jia et al. developed airborne weapon CAPP system and met the application of an aviation enterprise [19]. Xia et al. investigated the research of release safety analysis method for external stores of weapon [20-22]. Luo developed 1553B bus error correction technique in the management system of aircraft weapon to increase the adaptability between the aircraft and external plug [23].

Concentrating on the plug mode based on various missions for fighters with much heavy fuel load or quite a few weapons, a method based on RSA is designed and used to solve the optimization plug mode for minimum changing aircraft center of gravity.

In this paper, the design mode and objective function are presented in Section 2; and then the method for solving the optimization problem is performed in Section 3; the optimization results are analyzed in detail in Section 4; finally, the manuscript is concluded in Section 5.

\section{Design Mode and Objective Function}

The plug mode is defined as the corresponding relations between external loads and plug positions where the external loads include fuel and weapons loads such as common size auxiliary fuel tanks, various missiles, and bombs. The schematic of plug and spare load for a fighter on active service in current research is shown in Figure 1. European EF-2000 is selected as the fighter support, with empty weight 11.150 ton, 13 plug positions, and two types of external fuel tank. The coordinate of aircraft center of gravity can be calculated as

$$
\begin{aligned}
& X_{C} \\
& =\frac{M_{e} \cdot X_{e}+M_{\mathrm{if}} \cdot X_{\mathrm{if}}+\sum_{1}^{p} M_{\mathrm{ef}_{i}} \cdot X_{\mathrm{ef}_{i}}+\sum_{1}^{q} M_{\mathrm{ew}_{j}} \cdot X_{\mathrm{ew}_{j}}}{M_{s}},
\end{aligned}
$$

$$
M_{s}=M_{e}+M_{\mathrm{if}}+\sum_{1}^{p} M_{\mathrm{ef}_{i}}+\sum_{1}^{q} M_{\mathrm{ew}_{j}},
$$

where $X_{C}$ is the coordinate of aircraft center of gravity, $M_{e}$ is the aircraft empty weight, $X_{e}$ is the coordinate of aircraft center of gravity with empty weight, $M_{\text {if }}$ is the total weight of internal fuel, $X_{\text {if }}$ is the equivalent coordinate of internal fuel, $M_{\text {ef }}$ is the external fuel weight, $X_{\text {ef }}$ is the coordinate of the external fuel plug, $M_{\mathrm{ew}}$ is the weight of external weapon, $M_{\mathrm{ew}}$ is the coordinate of external weapon, $M_{s}$ is the total weight of the current aircraft.

Generally, the position of aircraft center of gravity is defined as a percentage of mean aerodynamic chord length:

$$
\begin{aligned}
C & =\frac{X_{L}-X_{C}}{L_{\mathrm{mac}}} \times 100 \%, \\
L_{\mathrm{mac}} & =X_{L}-X_{T},
\end{aligned}
$$

where $C$ is the position of aircraft center of gravity, $X_{L}$ is the coordinate of the leading edge of mean aerodynamic chord, $L_{\text {mac }}$ is the length of mean aerodynamic chord, and $X_{T}$ is the trailing edge of mean aerodynamic chord.

By using symmetrical loading, there are 7 plug positions to carry weapons or fuel tanks as shown in Figure 1. With specific task, external fuel and weapons can be determined. Then plug mode can be designed as

$$
\begin{aligned}
M & =\left[M_{1}, \ldots, M_{7}\right], \\
M_{i} & \in\left[M_{\mathrm{ef}_{1}}, \ldots, M_{\mathrm{ef}_{p}}, M_{\mathrm{ew}_{1}}, \ldots, M_{\mathrm{ew}_{q}}\right], \\
X & =\left[X_{1}, \ldots, X_{7}\right] .
\end{aligned}
$$

The plug mode, namely, the one-to-one correspondence between $M_{i}$ and $X_{i}, i=1,2, \ldots, 7$, can be solved by 


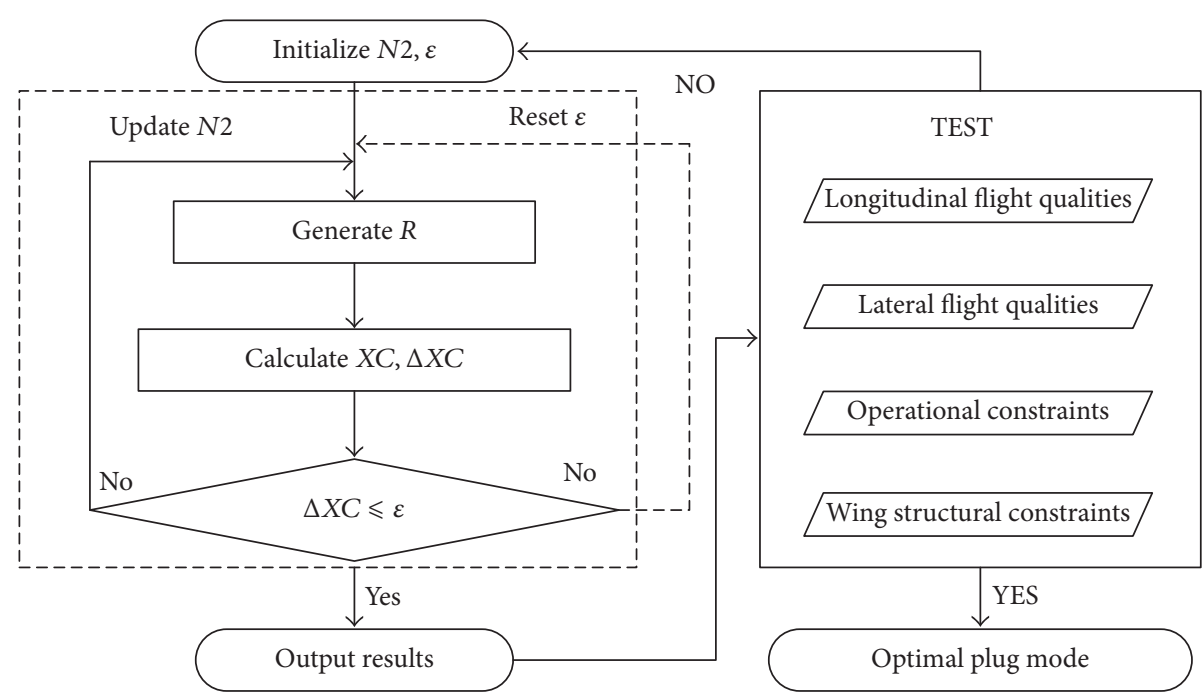

FIGURE 2: The flow chart of the random search algorithm and results test.

determining the array of $M_{i}$ and the center of gravity can be calculated by the combination of $M$ and $X$ based on formula (1).

\section{Methods for Solving Optimization Problem}

Because of various types of missiles and different missions, the group of $M$ and $X$ can reach hundreds of thousands or more, from the theoretical perspective regardless of plug position limit, including the fixed position of heavy external fuel tank or some anti-ship missile. Supposing the weight of internal fuel equals zero and all the plug positions mounted with weapons or fuel tanks, the optimization plug mode can be solved by the following methods.

3.1. Full Array Method. For giving mission and fixed type of external fuel load and weapon, the number of the group of $M$ and $X$ is an arrangement number, from the theoretical perspective. And a fixed plug position can be considered as cutting the length of the array of $X$. Then the matrix of all the group of $M$ and $X$ can be expressed as

$$
\begin{aligned}
F & =\operatorname{FAM}(M), \\
N_{0} & =A_{m}^{n}, \\
N_{1} & =A_{n}^{n}, \\
N_{2} & \leq \frac{N_{0}}{10},
\end{aligned}
$$

where FAM is a function to list all the array of $M, F$ is $N_{1} \times 7$ matrix, $N_{0}$ is the number of plug modes in different missions, $N_{1}$ is the number of plug modes in giving missions, $N_{2}$ is the number of plug modes by RA, $n$ is the number of active plugs, and $m$ is the number of all the types of external fuel tanks and weapons. According to (1)-(3), the center of gravity and minimum change of center of gravity can be calculated as

$$
\begin{aligned}
\Delta X_{C_{j}} & =X_{C_{j}}-X_{C 0}, \\
\Delta X_{C_{n 1}} & =\min \left(\Delta X_{C_{1}}, \ldots, \Delta X_{C_{N_{1}}}\right),
\end{aligned}
$$

where $X_{C 0}$ is the aircraft center of gravity with a typical plug mode under the giving mission.

3.2. Random Search Algorithm. Taking into account EF-2000 fighter, the value of $m$ can reach 17; then it is formidable for FAM to couple with the huge number $N_{0}$. Therefore, RSA is designed to search the optimization plug mode in a small samples. For a giving mission and optional types of external fuel load and weapons, RSA is designed and used to solve the optimization plug mode as shown in Figure 2.

Here $N_{2}$ is a random number or a giving number, $\varepsilon$ is critical error of center of gravity change, and $R$ is $N_{2} \times 7$ random matrix by arrangement of $M$ as described in (7). Similarly, the center of gravity and minimum change of center of gravity can be calculated as

$$
\begin{aligned}
R & =\operatorname{RSA}(M), \\
\Delta X_{C_{j}} & =X_{C_{j}}-X_{C 0}, \\
\Delta X_{C_{n 2}} & =\min \left(\Delta X_{C_{1}}, \ldots, \Delta X_{C_{N_{2}}}\right) .
\end{aligned}
$$

The RSA operator can proceed as follows.

Step 1. Obtain or update $N_{2}$ value.

Step 2. For each $i=1,2, \ldots, N_{2}$,

$R_{i}=t\left[M_{1}, M_{2}, \ldots, M_{j}\right], 1 \leq j \leq 7$; here $j$ is determined by the number and type of plugs 
TABLE 1: A typical plug load.

\begin{tabular}{lccccc}
\hline & & Weapon & & \multicolumn{2}{c}{ Fuel } \\
& AIM-9 & AIM-120 & Paveway & Tank 1 & Tank 2 \\
\hline Weight/ton & 0.0910 & 0.1507 & 0.9070 & 0.7750 & 1.1625 \\
Number & 2 & 4 & 4 & 2 & 1 \\
\hline
\end{tabular}

TABLE 2: The distribution of the typical plug load.

\begin{tabular}{|c|c|c|c|c|c|c|c|}
\hline \multicolumn{8}{|c|}{ Typical plug mode } \\
\hline$X$ & 1 & 2 & 3 & 4 & 5 & 6 & 7 \\
\hline Plug & AIM-9 & Paveway & $\begin{array}{c}\text { Tank } \\
1\end{array}$ & Paveway & $\begin{array}{c}\text { AIM- } \\
120\end{array}$ & $\begin{array}{c}\text { AIM- } \\
120\end{array}$ & $\begin{array}{c}\text { Tank } \\
2\end{array}$ \\
\hline
\end{tabular}

and $t$ is a true random operator to generate a set of nonrepeating permutations to simulate the various plug mode.

Step 3. Calculate $C$ and $\varepsilon$ for each $R_{i}$.

Step 4. Determine the optimal plug mode with the minimum absolute value of $\varepsilon$ among $R$.

Concerning that the valve of $N_{2}$ is not large enough to find the optimization solution, $N_{2}^{\prime}$ is used to update $N_{2}$ to search one more time until meeting the error test. Even if the above 4 steps still cannot get the answer, resetting $\varepsilon$ can be available to continue the algorithm. The updating and resetting operator for $\mathrm{N}_{2}$ can be described as follows:

$$
\begin{aligned}
N_{2}^{\prime} & =r \cdot N_{2}, \\
r & = \begin{cases}5 & \Delta X_{C_{n 2}}>\varepsilon \\
0 & \Delta X_{C_{n 2}} \leq \varepsilon .\end{cases}
\end{aligned}
$$

The optimization plug mode can be determined based on (9) with the termination of the random search algorithm. In addition, the ultimatum solution of the optimal plug mode should pass the results test such as flight qualities and operational and wing structural constrains as shown in Figure 2.

\section{Results and Analysis}

4.1. The Results of Typical Plug Mode. For comparison of the solutions between RSA and FAM, a typical plug load including 10 missiles and 3 external fuel tanks is given as shown in Table 1. There are 10 missiles and 3 fuel tanks for the fighter to possess plenty of missiles and fuel. By using symmetrical loading, the typical plug mode is presented in Table 2.

Regarding (1)-(3), the center of gravity in the typical plug mode is calculated to be $17.7205 \%$, where $C_{e}=19.50 \%$. Then $\Delta C_{0}=-1.7795 \%$.

4.2. The Results and Analysis of FAM. To obtain the precise solution of the typical plug mode, FAM is used to produce

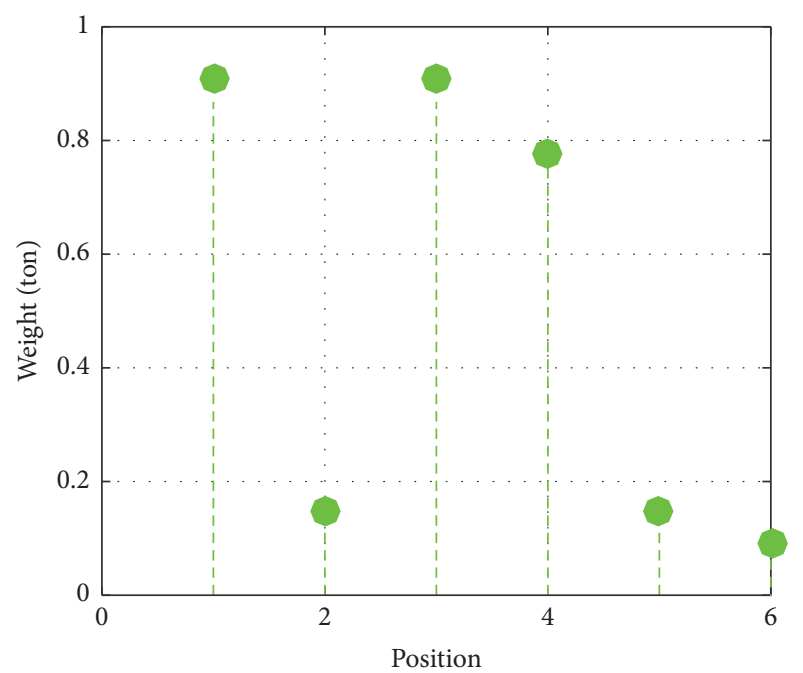

FIgURE 3: Precise plug mode.

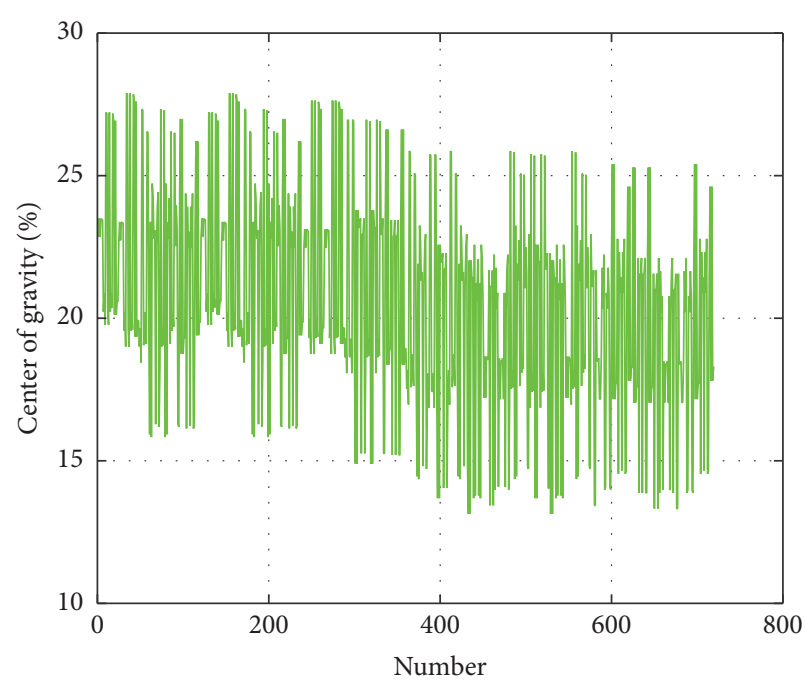

FIGURE 4: Center of gravity by FAM.

all the array of $M$ matrix. Concerning the fact that there is a unique position $\left(X_{7}\right)$ for fuel tank 2 as shown in Figure 1 and Table 2, the value of $N_{1}$ is 720 . With this in mind, the precise plug mode can be determined as presented in Figure 3. The results of center of gravity are obtained as shown in Figure 4 with a range of $13.1343 \%-27.8909 \%$. The change of $C$ is presented in Figure 5 in the scope [-6.3657, 8.3909]. To observe the range of $C$, the results of center of gravity is sorted as shown in Figure 6. Besides, there are 164 plug modes with less changing of the value of $C$ than the typical plug mode. Then the minimum change of $C$ can be determined as $0.0594 \%$ where $C=19.5594 \%$ with the precise plug mode. Because $F$ matrix is a full arrangement of $M$, the precise solution can be considered reliable.

4.3. The Results and Analysis of RSA. Figure 7 shows that it is formidable to search the robust results of plug mode when the initial size of $N_{2}$ is small. Thanks to the action 
TABLE 3: Center of gravity generations of the optimization plug mode by RSA.

\begin{tabular}{lcccc}
\hline Generations & 1 & 2 & 3 & 4 \\
\hline$N_{2}$ & 4 & 20 & 100 & 500 \\
$C / \%$ & 22.3846 & 19.9799 & 19.5605 & 19.5605 \\
$\Delta C / \%$ & 2.8846 & 0.4799 & 0.0605 & 0.0605 \\
$\varepsilon / \%$ & 14.748 & 2.454 & 0.309 & 0.309 \\
\hline
\end{tabular}

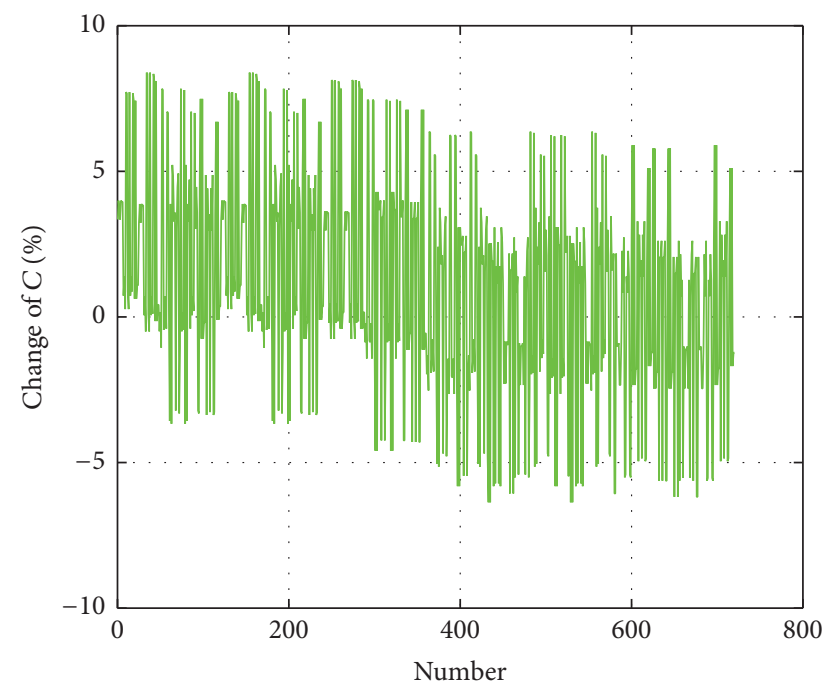

Figure 5: Change of $C$ by FAM.

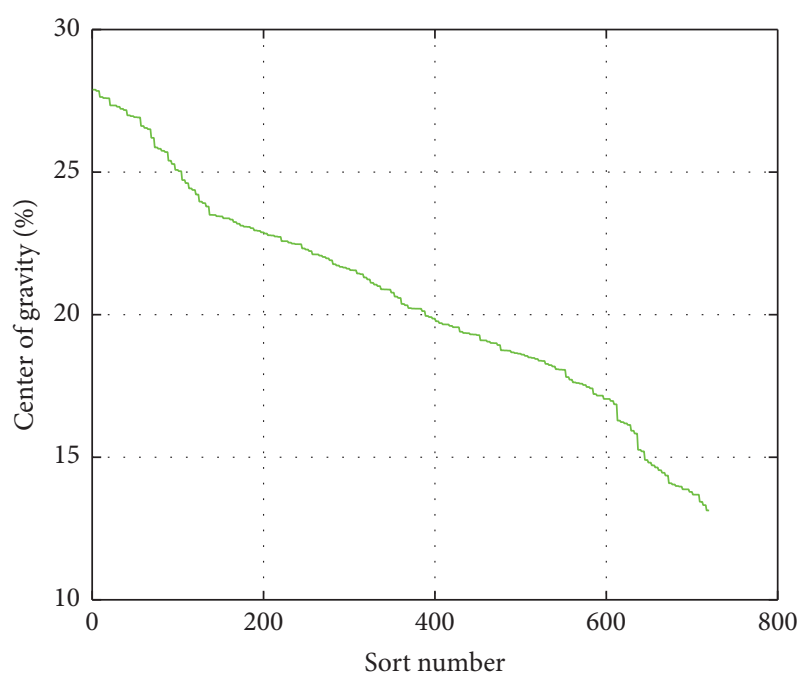

FIGURE 6: Sorting results of center of gravity by FAM.

of updating and resetting operator of $N_{2}$, the relative error of the optimal $C$ is significantly reduced when the value of $\mathrm{N}_{2}$ increases to 20 as shown in Table 3. Figure 8 presents the fact that there are more solutions close to the value $C=19.5594 \%$ by FAM. In addition, the error is significantly improved when $N_{2} \geq 20$ from Table 3 and the proposed algorithm is theoretically and practically convergent. Figure 9 supports the fact that a new plug mode can be applied to

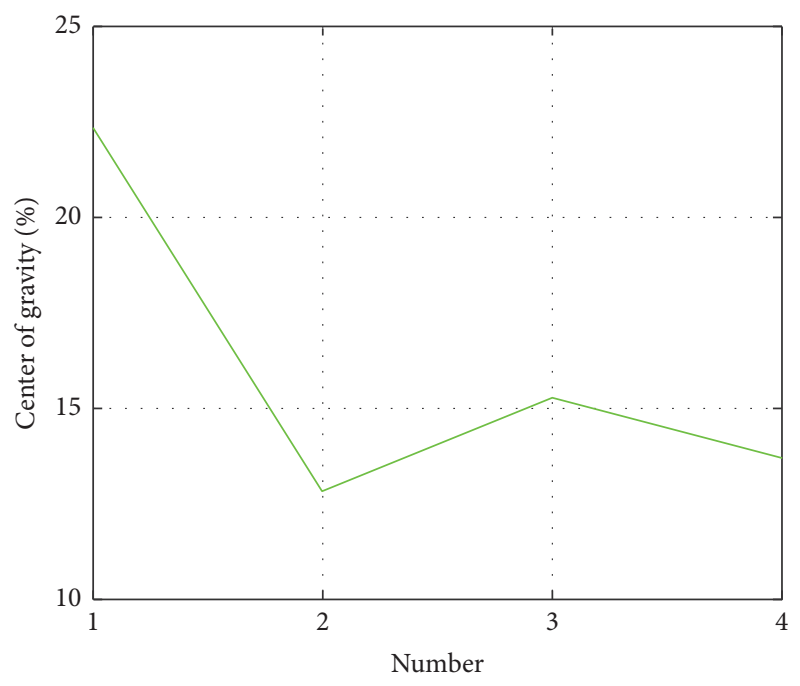

FIgure 7: Center of gravity by RSA, $N_{2}=4$.

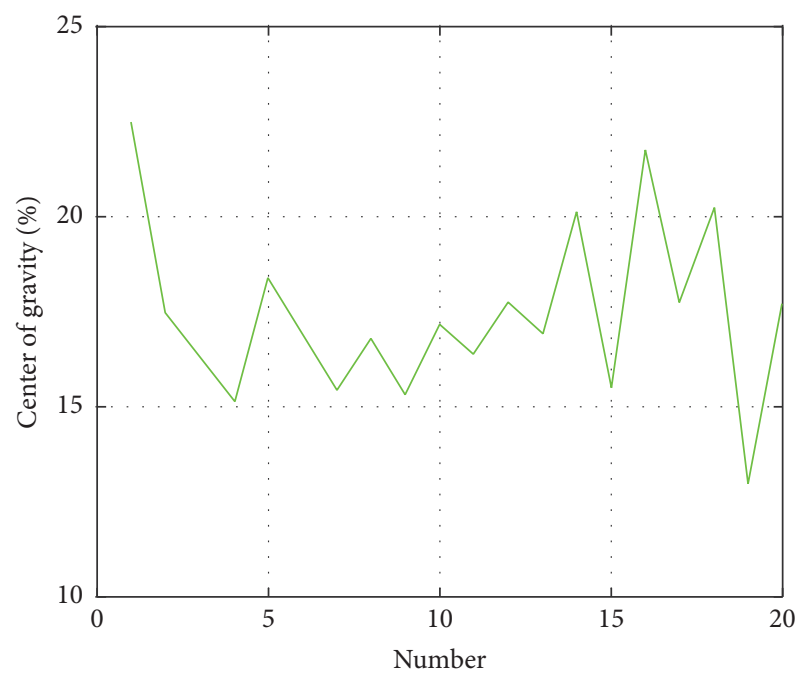

Figure 8: Center of gravity by RSA, $N_{2}=20$.

finish the external load distribution when it is suitable for $X_{6}$ plug position to carry Paveway missile, including the strength of the plug pylons and the space around the plug point. Unlike the other random search method for producing some single values, the RSA operator concentrates on generating a certain number of nonrepeating combinations to simulate the various and promising plug modes. It can be noted from Figure 10 that the center of gravity ranges from $12.4865 \%$ to $22.4288 \%$ close to the result by FAM. Figure 11 shows that the value of $\Delta C$ is between $-7.0135 \%$ and $2.9288 \%$. It could be remarkable from Figure 12 that there are 59 plug modes which changes center of gravity less than the typical plug mode by comparing the absolute value of $\Delta C$ between RSA and the typical plug mode. The minimum value of center of gravity position can reach $19.5605 \%$ with $\Delta C=0.0605 \%$ which is close to the solution by FAM. Furthermore, it just costs RSA 100 initial plug modes to get the optimization solution by searching only one time. Compared with FAM, RSA is really fast and efficient with enough precision. 


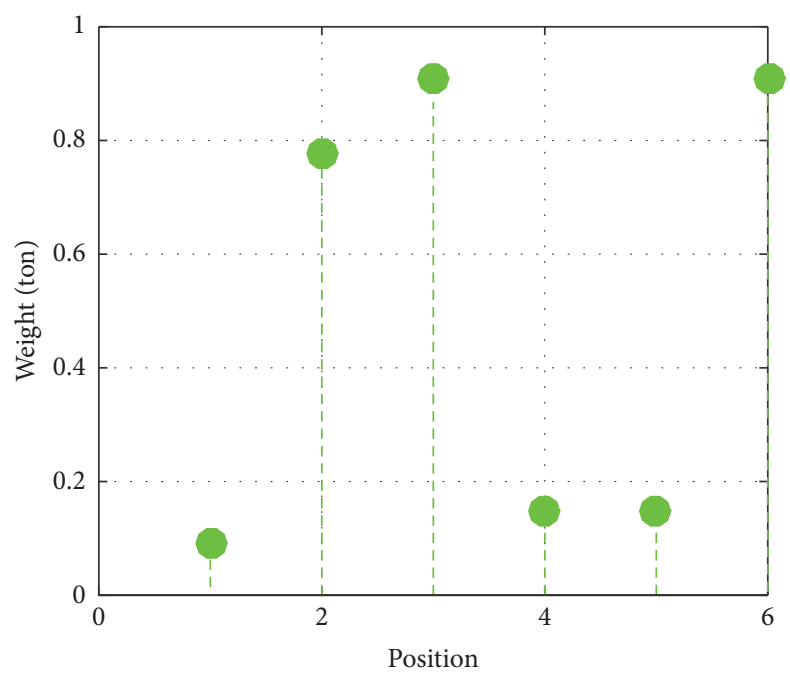

FIgURE 9: The optimization plug mode, $N_{2}=100$.

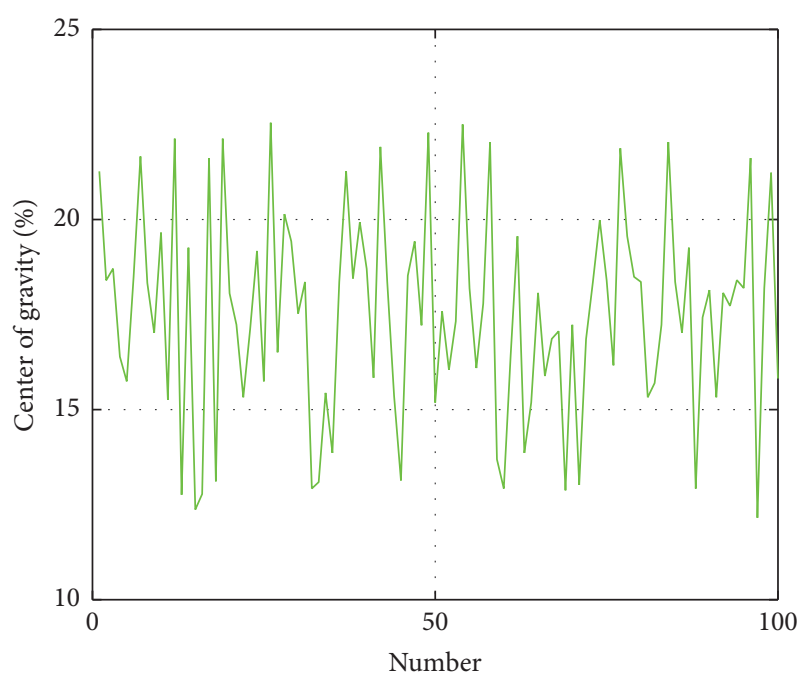

Figure 10: Center of gravity by RSA, $N_{2}=100$.

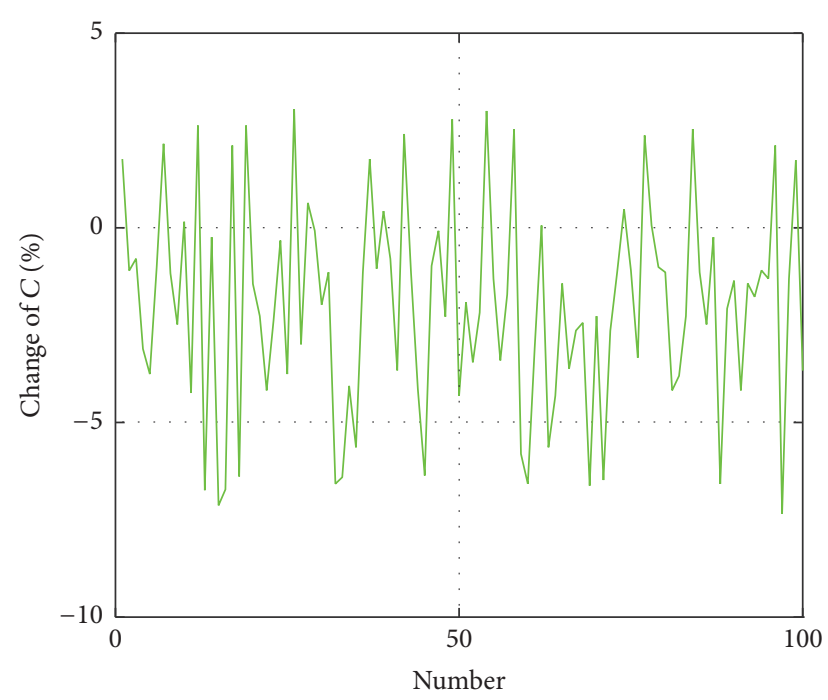

Figure 11: Change of $C$ by RSA, $N_{2}=100$.

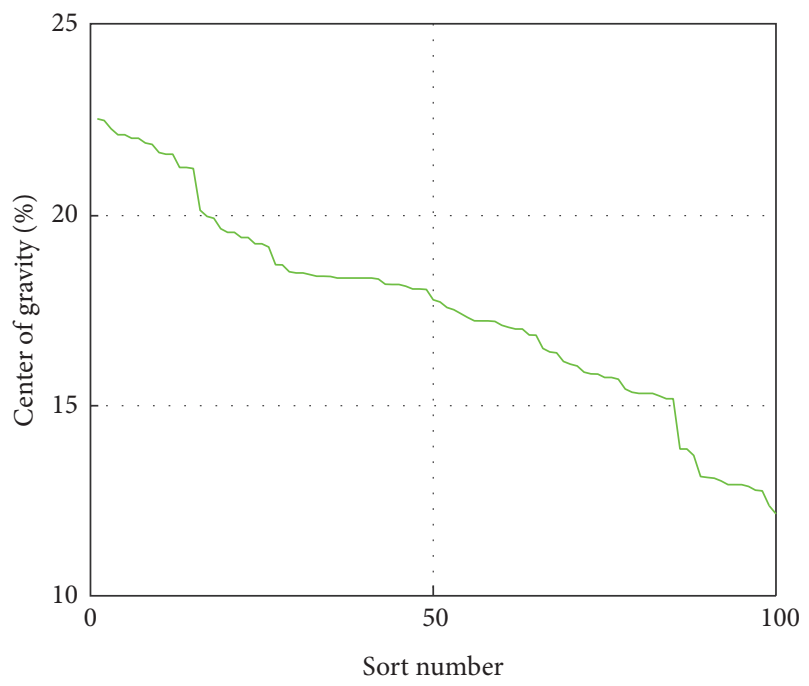

FIGURE 12: Sort center of gravity by RSA, $N_{2}=100$.

Figure 13 supports the fact that there are 13 plugs occupying all the plug positions not only to simulate aircraft high payload but also to test the proposed algorithm. By pouring attention to the weight of Paveway missile heavier than that of fuel tank 1 in spite of the former volume smaller than the later, $X_{2}$ or $X_{4}$ plug position is strong enough to carry the other plugs lighter than fuel tank 1 from the perspective of wing structure and this is operable. In addition, the high weight of Paveway plug at $X_{2}$ position is not good for rolling manipulation, thus affecting the lateral flight qualities. Figure 14 indicates that a precise plug mode with the minimum changing center of gravity is obtained by FAM. Although the longitudinal flight qualities are improved because of the minimum changing aircraft center of gravity, the heavy weight of Paveway missile at $X_{1}$ position is extremely detrimental to the lateral flight qualities as shown in FAM results. In addition, high load often occupying the wing tip is unfavorable for aircraft wing structure and easily leads to structural fatigue along with the aircraft taking off, climbing, and maneuvering. Thanks to the optimal solution by RSA, the disadvantages above are well improved as shown in RSA results. As previously demonstrated, $X_{2}$ is strong enough to carry fuel tank 1 lighter than the Paveway missile and the auxiliary tank could be preferentially exhausted and abandoned; thus the flight qualities could be improved significantly. The remaining operation is placing the Paveway missile at $X_{6}$ position and this is convenient and feasible.

\section{Conclusions}

RSA for solving the optimization plug mode was carried out. A typical plug mode was used to be the comparison of reference between RSA and FAM. FAM is precise and comprehensive to calculate the precise solution with computing a large number of the arrangements of $M$. RSA is accurate and efficient for generating the optimization plug mode with searching among a small number of samples of the arrangement of $M$. From this research, it can be found that 

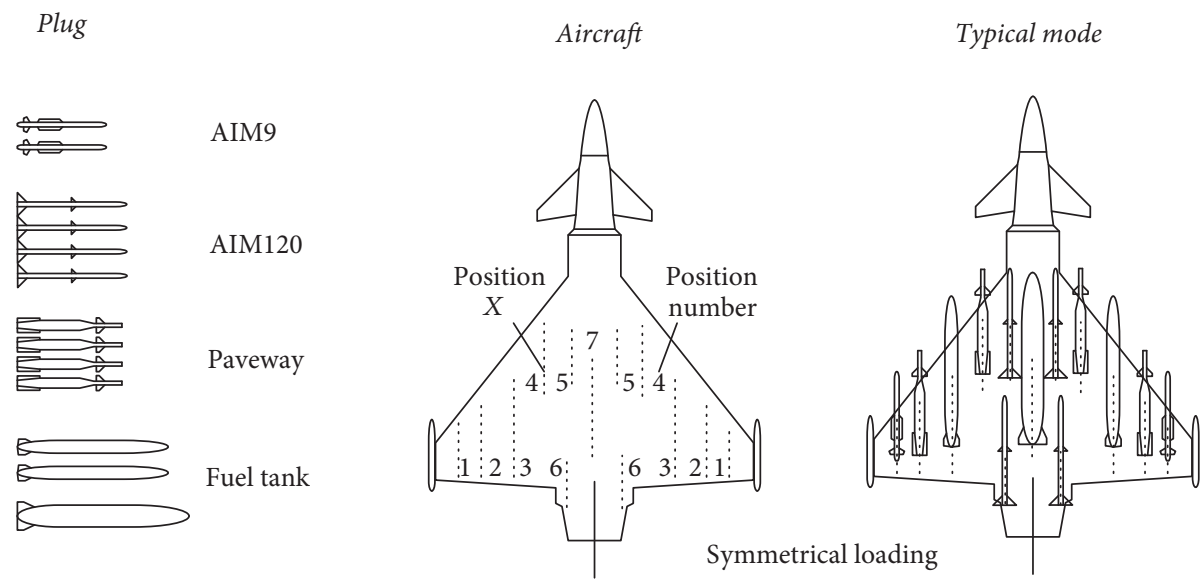

FIGURE 13: The schematic of aircraft, plug, plug position, and typical plug mode.
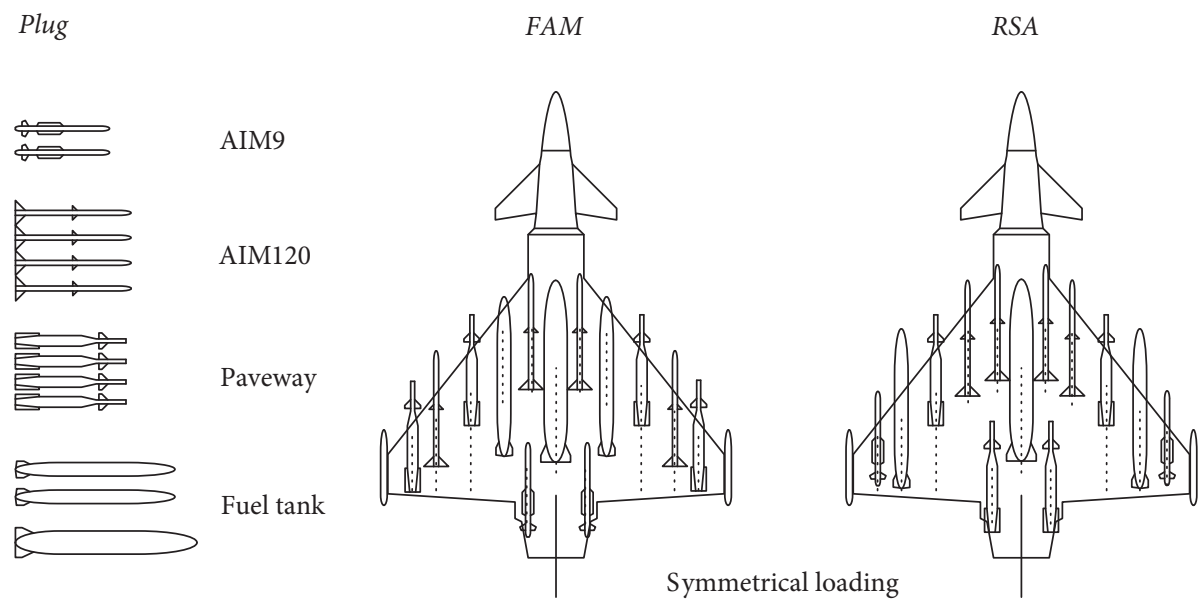

FIGURE 14: Comprehensive analysis and comparison of the results by FAM and RSA.

RSA coupled with FAM is an efficient tool for optimization of aircraft plug mode.

\section{Disclosure}

This research received no specific grant from any funding agency in the public, commercial, or not-for-profit sectors.

\section{Conflicts of Interest}

The authors declare that there are no conflicts of interest.

\section{References}

[1] C. Han, L. Yang, and J. Zhang, "Adaptive nonsingular fast terminal sliding mode control for aircraft with center of gravity variations," Proceedings of the Institution of Mechanical Engineers, Part G: Journal of Aerospace Engineering, vol. 229, no. 1, pp. 4-9, 2015.

[2] X. Yang, M. Luo, J. Zhang, and L. Yang, "Aircraft centre-ofgravity estimation using Gaussian process regression models," in Proceedings of the IEEE International Conference on Aircraft
Utility Systems (AUS '16), pp. 991-995, IEEE, Beijing, China, October 2016.

[3] Aircraft weight and center of gravity indicator system, U.S. Patent 3,701,279. 1972-10-31.

[4] A. Gupta, C. Moreno, H. Pfifer, B. Taylor, and G. J. Balas, "Updating a finite element based structural model of a small flexible aircraft," in Proceedings of the AIAA Science and Technology Forum.

[5] Y. Z. Li, C. S. Yuan, and L. Zhang, "Analyze the C.G of a UAV based on load task," Science Technology and Engineering, vol. 11, no. 15, pp. 3472-3475, 2011.

[6] H. Li, J. Zhang, and J. Yan, "Effects of partial fuel pump failure on center of gravity control for high-speed aircraft," in Proceedings of the International Conference on Aircraft Utility Systems (AUS), pp. 146-150, IEEE, 2016.

[7] H. Li, J. Zhang, and J. Yan, "Analysis of the influence of partial fuel transfer line leak on active center of gravity control," in Proceedings of the International Conference on Aircraft Utility Systems (AUS), pp. 151-155, IEEE, Beijing, China, October 2016.

[8] A. Jungo, F. P. Gallaire, and J. Vos, Development of the CEASIOM aircraft design environment for novel aircraft configurations [D]. [Master, thesis], Ecole polytechnique federale de Lausanne, 2014. 
[9] P. Mardanpour, D. H. Hodges, R. Neuhart, and N. Graybeal, "Engine placement effect on nonlinear trim and stability of flying wing aircraft," Journal of Aircraft, vol. 50, no. 6, pp. 17161725, 2013.

[10] Q. C. Zhen, "Probe into the C.G. position of minimum drag for J-7 aircraft," Flight Dynamics, vol. 3, pp. 40-46, 1991.

[11] G. Sachs, "Minimum trimmed drag and optimum c.g. position," Journal of Aircraft, vol. 15, no. 8, pp. 456-459, 1978.

[12] W. J. Xu and Z. M. Liu, "Effect of center-of-gravity position on aircraft drag and flight performance," Flight Dynamics, vol. 17, no. 1, pp. 54-58, 1999.

[13] G. Wang, Y. Hu, and B. Song, "Tailless UAV design optimization under center of gravity location uncertainty," Acta Aeronautica et Astronautica Sinica, vol. 36, no. 7, pp. 2214-2224, 2015.

[14] J. H. Diekmann, "Trim analysis of nonlinear flight dynamics for a civil aircraft with active high-lift system," in Deutscher Luft- und Raumfahrtkongress, Stuttgart, Deutschland, September 2013.

[15] J. Y. Tang, C. Z. Wang, B. Wang, and etal., "Methods of calculating and analysis of aircraft's gravity position," Aeronautical Computing Technique, vol. 46, no. 3, pp. 72-74, 2016.

[16] B. D. Dancila, R. Botez, and D. Labour, "Fuel burn prediction algorithm for cruise, constant speed and level flight segments," Aeronautical Journal, vol. 117, no. 1191, pp. 491-504, 2013.

[17] R. F. Patron, R. Botez, and D. Labour, "Low calculation time interpolation method on the altitude optimization algorithm for the FMS CMA-9000 improvement on the A310 and L-1011 aircraft," in Proceedings of Aviation Technology, Integration and Operation (ATIO) Conference and International Powered Lift Conference (IPLC), Los Angeles, CA, USA.

[18] C. Ivester, J. Mckee, W. Johnson et al., Compact aircraft galley and lavatory arrangement and articulating lavatory partition for an aircraft, U.S. Patent Application 14/175,537. 2014:2-7.

[19] X. L. Jia, L. J. Huang, Z. M. Zhang, and et al., "Development and Application of CAPP system for aircraft airborne weapon gallows product," Aviation Precision Manufacturing Technology, vol. 44, no. 2, pp. 52-55, 2008.

[20] L. Xia, "Analysis the effect of carrying and launching weapon on the stability and motion parameter of helicopter," Flight Dynamics, no. 3, pp. 33-41, 1990.

[21] M. Zhang, L. Wang, D. Ren, and et al., "Design and realization of weapon store simulator," Trainer, no. 4, pp. 46-49, 2013.

[22] W. L. Feng, J. L. Cheng, and L. Y. Lv, "Safety analysis method in weapons store delivery," Journal of Projectiles, Rockets, Missiles and Guidance, vol. 34, no. 4, pp. 191-195, 2014.

[23] Z. Q. Luo, "1553B bus error correction technology in the management system of aircraft weapon," Electronics Optics \& Control, vol. 3, 1987. 


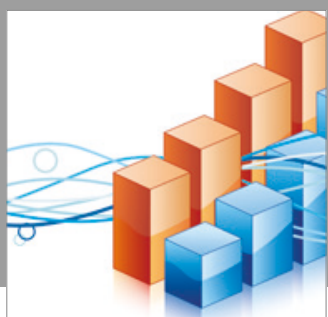

Advances in

Operations Research

vatersals

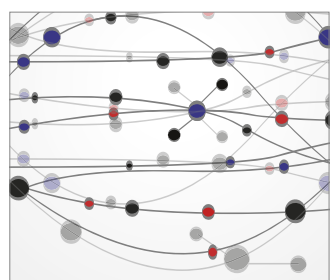

\section{The Scientific} World Journal
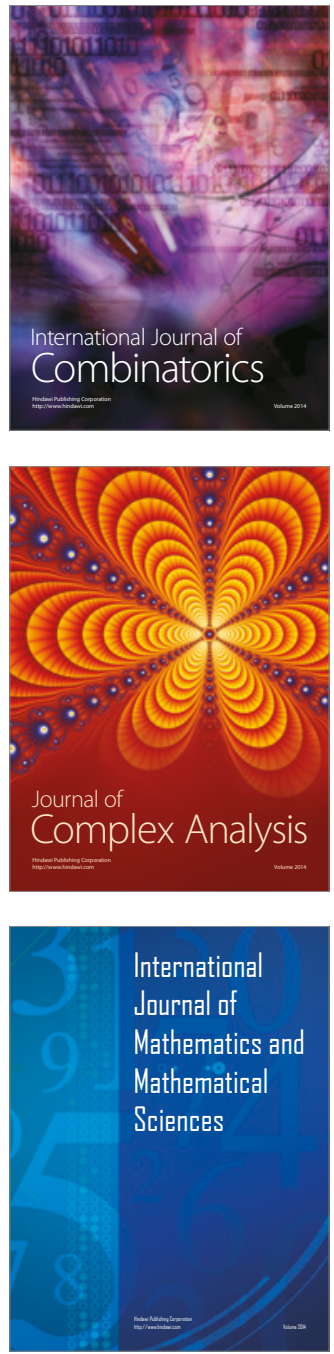
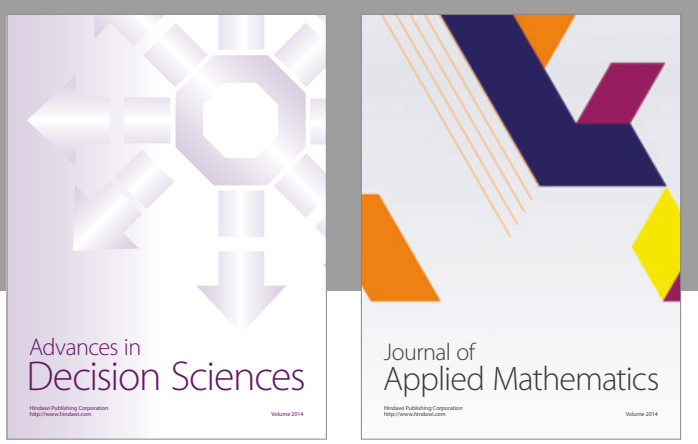

Algebra

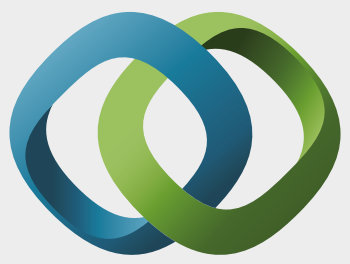

\section{Hindawi}

Submit your manuscripts at

https://www.hindawi.com
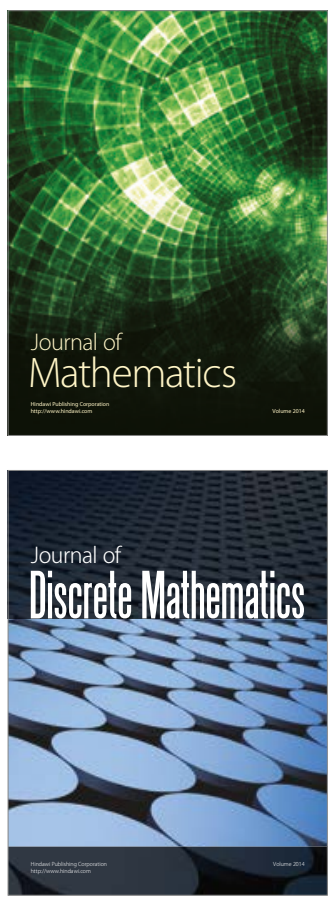

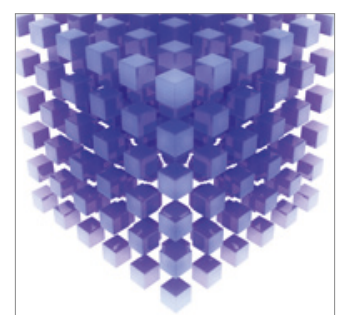

Mathematical Problems in Engineering
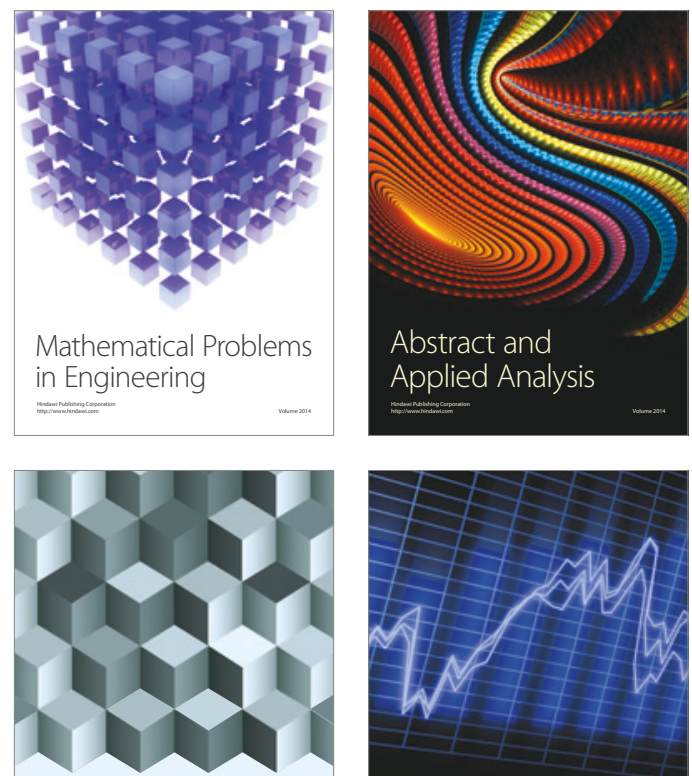

Journal of

Function Spaces

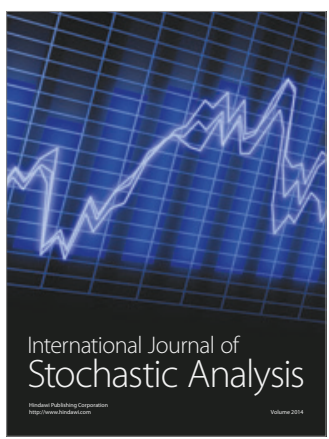

Probability and Statistics
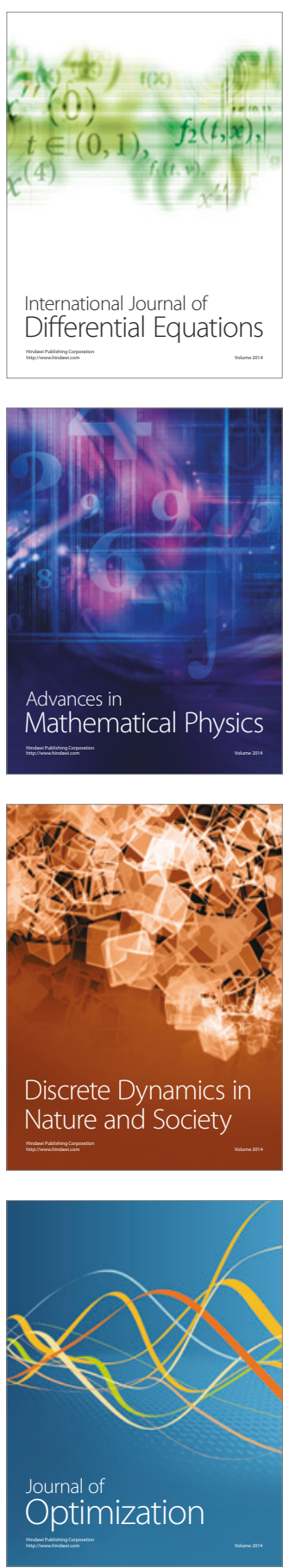